\title{
Gene Therapy for Pancreatic Diseases: Current Status
}

\author{
Kenya Kamimura*(D), Takeshi Yokoo ${ }^{(\mathbb{D}}$ and Shuji Terai \\ Division of Gastroenterology and Hepatology, Graduate School of Medical and Dental Sciences, \\ Niigata University, 1-757, Aasahimachi-Dori, Chuo-Ku, Niigata 951-8510, Japan; \\ t-yokoo@med.niigata-u.ac.jp (T.Y.); terais@med.niigata-u.ac.jp (S.T.) \\ * Correspondence: kenya-k@med.niigata-u.ac.jp; Tel.: +81-25-227-2207; Fax: +81-25-227-0776
}

Received: 1 October 2018; Accepted: 29 October 2018; Published: 31 October 2018

check for updates

\begin{abstract}
The pancreas is a key organ involved in digestion and endocrine functions in the body. The major diseases of the pancreas include pancreatitis, pancreatic cancer, cystic diseases, pancreatic divisum, islet cell tumors, endocrine tumors, diabetes mellitus, and pancreatic pain induced by these diseases. While various therapeutic methodologies have been established to date, however, the improvement of conventional treatments and establishment of novel therapies are essential to improve the efficacy. For example, conventional therapeutic options, including chemotherapy, are not effective against pancreatic cancer, and despite improvements in the last decade, the mortality rate has not declined and is estimated to become the second cause of cancer-related deaths by 2030. Therefore, continuous efforts focus on the development of novel therapeutic options. In this review, we will summarize the progress toward the development of gene therapies for pancreatic diseases, with an emphasis on recent preclinical studies and clinical trials. We aim to identify new areas for improvement of the current methodologies and new strategies that will lead to safe and effective gene therapeutic approaches in pancreatic diseases.
\end{abstract}

Keywords: gene therapy; pancreas; cancer; pancreatitis; diabetes mellitus; pain

\section{Introduction}

The pancreas is a key organ involved in digestion and endocrine functions, located in the retroperitoneal space, and measures approximately $15-20 \mathrm{~cm}$ in length. The pancreatic duct, that runs along the organ, connects to the duodenum. One major function of the pancreas is digestion of proteins, fats, and carbohydrates by enzymes released through the duct. A second important role of the pancreas is endocrine activity mediated by several hormones, such as insulin, released from the pancreatic glands to the blood circulation, which help maintain the homeostasis in the body. Major diseases of the pancreas include pancreatitis, pancreatic cancer, cystic diseases, pancreatic divisum, islet cell tumors, endocrine tumors, and diabetes mellitus [1].

Among the pathologies involving the pancreas, pancreatic cancer is one of the leading causes of the cancer-related deaths globally and currently is the fourth cause of cancer-related mortalities in the United States [2]. Pancreatic ductal adenocarcinoma, the most common histological type, has a poor prognosis and aggressive growth pattern [3]. Although poor glycemic control and weight loss in patients with long-standing diabetes were proposed as useful markers for pancreatic cancer [4], there are currently no markers or strategies that can detect the tumor in the early phase. In addition, although depletion of adipose and skeletal muscle tissues in the early stages of cancer is common, recent evidence suggests that early loss of peripheral tissue in association with pancreatic cancer may not impair survival [5]; therefore, a better understanding of the mechanism underlying the progression of this aggressive cancer is essential. Recent epidemiological studies clearly show that the mortality rate of pancreatic cancer is not declining, and pancreatic cancer is estimated to become the second 
cause of cancer-related deaths by 2030 [6]. Therefore, significant effort is spent on the development of novel therapeutic options for this devastating disease.

Although several novel chemotherapeutic compounds, including nab-paclitaxel and liposomal irinotecan, and chemotherapy regimens, such as FOLFIRINOX, have been successfully tested in clinical trials as conventional treatment options [7], the prognosis remains poor [8]. To improve the prognosis of pancreatic cancer, the number of basic researches and clinical trials are increasing [7]. In addition, the comprehensive precision medicine tools for therapeutic options that have been implemented in both the community and academic areas [9] have led to better progression-free survival rates in patients receiving matched therapy.

In a disease where novel therapeutic innovations are sorely needed, combining novel therapies, including gene and cell therapy approaches, with the currently available cytotoxic chemotherapeutic drugs and radiation therapy, provides hope for better outcomes in patients with advanced-stage pancreatic cancer. Among such potentially innovative treatment approaches, gene therapy offers a promising avenue based on the results of several completed and ongoing clinical trials. The summaries of these studies are shown in Tables 1 and 2.

Preclinical studies have led to a better understanding of pancreatic cancer, as well as potential therapeutic target genes, including tumor suppressor genes, antiangiogenic and pro-apoptotic genes, and suicide genes [10]. A study including 3030 patients with pancreatic cancer showed significant associations with germline mutations in CDKN2A, TP53, MLH1, BRCA2, ATM, and BRCA1 and the risk of the cancer occurrence [11]. Similar results have been reported in studies focusing on the role of KRAS gene in tumor development [12], and research on inactivation of the DNA maintenance genes, including $B R C A 1, B R C A 2$, and PALB2, demonstrated that patients with pancreatic cancer with defective DNA maintenance genes responded better to platinum-based chemotherapy [13]. In addition, preclinical studies led to the identification of potential therapeutic target genes. For example, downregulation of the microRNA, miR-98-5p promoted pancreatic tumor development by downregulation of MAP4K4 and inhibition of the downstream MAPK/ERK signaling, suggesting that the miR-98-5p can be a therapeutic target in pancreatic cancer treatment [14]. Similarly, spalt-like protein 4 induced endothelial-mesenchymal transitions to facilitate metastatic potential in pancreatic ductal adenocarcinoma (PDAC) cells, indicating that spalt-like protein 4 might be a marker for PDAC treatment and that targeting this protein might benefit anti-proliferative and anti-metastasis therapies [15]. A study demonstrated that the knockout of epithelial cell transforming 2 gene by the clustered regularly interspaced short palindromic repeats/CRISPR associated protein 9 (CRISPR/Cas9) gene editing method decreased proliferation and ability to migrate in the MiaPaCa2 pancreatic cancer cell line [16]. Furthermore, three intratumoral infiltrating immune markers (CD15, CD206 and CD117) and one SMAD4 mutation were found to be associated with recurrence and survival in patients after surgery for PDAC [17] and G protein alpha-driven oncogenic mechanisms, Siks revealed unanticipated metabolic heterogeneity among KRAS-mutant pancreatic neoplasms and evidenced to be a potent tumor suppressor [18]. 
Table 1. Summary of clinical trials published.

\begin{tabular}{|c|c|c|c|c|c|c|c|}
\hline No. & Ref. & Conditions & Title & Carrier & Interventions & Phases & Enrollment \\
\hline 1 & {$[19]$} & $\begin{array}{c}\text { Pancreatic } \\
\text { Cancer }\end{array}$ & $\begin{array}{l}\text { Gene therapy with Adv-IL-2 in unresectable digestive cancer: } \\
\text { phase I-II study, intermediate report. }\end{array}$ & Adenovirus & $\mathrm{AdV} /$ Interleukin 2 & Phase $1 /$ Phase 2 & 7 \\
\hline 2 & [20] & $\begin{array}{l}\text { Pancreatic } \\
\text { Cancer }\end{array}$ & $\begin{array}{l}\text { Safety and feasibility of injection with an E1B- } 55 \mathrm{kDa} \\
\text { gene-deleted, replication-selective adenovirus (ONYX-015) into } \\
\text { primary carcinomas of the pancreas: a phase I trial. }\end{array}$ & Adenovirus & AdV/ONYX-015 & Phase 1 & 23 \\
\hline 3 & {$[21]$} & $\begin{array}{l}\text { Pancreatic } \\
\text { Cancer }\end{array}$ & $\begin{array}{l}\text { Treatment of inoperable pancreatic carcinoma using a cell-based } \\
\text { local chemotherapy: results of a phase I/II clinical trial. }\end{array}$ & Lipofectamine (Plasmid DNA) & Lipofectamine/Cyto. P450 & Phase 1/Phase 2 & 14 \\
\hline 4 & [22] & $\begin{array}{l}\text { Pancreatic } \\
\text { Cancer }\end{array}$ & $\begin{array}{l}\text { Mucin gene (MUC1) transfected dendritic cells as vaccine: } \\
\text { results of a phase I/II clinical trial. }\end{array}$ & Cationic liposome (Plasmid DNA) & $\begin{array}{l}\text { Cationic liposome/dendritic cells } \\
\text { transfected with MUC1 cDNA }\end{array}$ & Phase $1 /$ Phase 2 & 10 \\
\hline 5 & [23] & $\begin{array}{l}\text { Pancreatic } \\
\text { Cancer }\end{array}$ & $\begin{array}{l}\text { A phase I/II trial of intratumoral endoscopic ultrasound } \\
\text { injection of ONYX-015 with intravenous gemcitabine in } \\
\text { unresectable pancreatic carcinoma. }\end{array}$ & Adenovirus & AdV/ONYX-015 + gemcitabine & Phase $1 /$ Phase 2 & 21 \\
\hline 6 & [24] & $\begin{array}{l}\text { Pancreatic } \\
\text { Cancer }\end{array}$ & $\begin{array}{l}\text { First clinical experience using a 'pathotropic' injectable } \\
\text { retroviral vector (Rexin-G) as intervention for stage IV } \\
\text { pancreatic cancer. }\end{array}$ & Retrovirus & Rv/Rexin-G & Phase 1 & 3 \\
\hline 7 & {$[25]$} & $\begin{array}{l}\text { Pancreatic } \\
\text { Cancer }\end{array}$ & $\begin{array}{l}\text { Phase I trial of intratumoral injection of an adenovirus } \\
\text { encoding interleukin-12 for advanced digestive tumors. }\end{array}$ & Adenovirus & AdV/Interleukin 12 & Phase 1 & 7 \\
\hline 8 & [26] & $\begin{array}{l}\text { Pancreatic } \\
\text { Cancer }\end{array}$ & $\begin{array}{l}\text { TNFerade biologic, an adenovector with a radiation-inducible } \\
\text { promoter, carrying the human tumor necrosis factor alpha gene: } \\
\text { a phase I study in patients with solid tumors. }\end{array}$ & Adenovirus & TNFerade & Phase 1 & 30 \\
\hline 9 & [27] & $\begin{array}{l}\text { Pancreatic } \\
\text { Cancer }\end{array}$ & $\begin{array}{l}\text { Intratumoral injection of dendritic cells engineered to secrete } \\
\text { interleukin- } 12 \text { by recombinant adenovirus in patients with } \\
\text { metastatic gastrointestinal carcinomas. }\end{array}$ & Adenovirus & Adv encoding interleukin- 12 gene & Phase 1 & 11 \\
\hline 10 & [28] & $\begin{array}{l}\text { Pancreatic } \\
\text { Cancer }\end{array}$ & $\begin{array}{l}\text { Poxvirus-based vaccine therapy for patients with advanced } \\
\text { pancreatic cancer. } \\
\text { Allogeneic granulocyte macrophage colony-stimulating }\end{array}$ & Vaccinia and Pox virus & $\begin{array}{l}\text { Vaccinia and Pox virus expressing CEA } \\
\text { MUC-1 and co-stimulatory molecules }\end{array}$ & Phase 1 & 10 \\
\hline 11 & [29] & $\begin{array}{l}\text { Pancreatic } \\
\text { Cancer }\end{array}$ & $\begin{array}{l}\text { factor-secreting tumor immunotherapy alone or in sequence } \\
\text { with cyclophosphamide for metastatic pancreatic cancer: a pilot } \\
\text { study of safety, feasibility, and immune activation. }\end{array}$ & Plasmid DNA & Plasmid/GVAX & Phase 1 & 50 \\
\hline 12 & [30] & $\begin{array}{l}\text { Pancreatic } \\
\text { Cancer }\end{array}$ & $\begin{array}{l}\text { Advanced phase I/II studies of targeted gene delivery in vivo: } \\
\text { intravenous Rexin-G for gemcitabine-resistant metastatic } \\
\text { pancreatic cancer. }\end{array}$ & Retrovirus & $\mathrm{Rv} /$ Rexin-G at two dosages & Phase $1 /$ Phase 2 & 9 \\
\hline 13 & [31] & $\begin{array}{l}\text { Pancreatic } \\
\text { Cancer }\end{array}$ & $\begin{array}{l}\text { A phase I dose-escalation clinical trial of intraoperative direct } \\
\text { intratumoral injection of HF10 oncolytic virus in non-resectable } \\
\text { patients with advanced pancreatic cancer. }\end{array}$ & Herpes virus & HF10 oncolytic herpes virus & Phase 1 & 6 \\
\hline 14 & [32] & $\begin{array}{l}\text { Pancreatic } \\
\text { Cancer }\end{array}$ & $\begin{array}{l}\text { Mutated Ras-transfected, EBV-transformed lymphoblastoid cell } \\
\text { lines as a model tumor vaccine for boosting T-cell responses } \\
\text { against pancreatic cancer: a pilot trial. }\end{array}$ & Immunotherapy & $\begin{array}{l}\text { Lymphocytes modified with an } \\
\text { episomal EBV expressing Ras mutant }\end{array}$ & Phase 1 & 7 \\
\hline 15 & [33] & $\begin{array}{l}\text { Pancreatic } \\
\text { Cancer }\end{array}$ & $\begin{array}{l}\text { Phase } 1 / 2 a \text {, dose-escalation, safety, pharmacokinetic and } \\
\text { preliminary efficacy study of intratumoral administration of } \\
\text { BC-819 in patients with unresectable pancreatic cancer. }\end{array}$ & Plasmid DNA & $\begin{array}{l}\text { Plasmid/expression of diphtheria-toxin } \\
\text { gene }\end{array}$ & Phase 1 & 9 \\
\hline 16 & [34] & $\begin{array}{l}\text { Pancreatic } \\
\text { Cancer }\end{array}$ & $\begin{array}{l}\text { EUS or percutaneously guided intratumoral TNFerade biologic } \\
\text { with } 5 \text {-fluorouracil and radiotherapy for first-line treatment of } \\
\text { locally advanced pancreatic cancer: a phase I/II study. } \\
\text { A live-attenuated Listeria vaccine (ANZ-100) and a }\end{array}$ & Adenovirus & AdV /TNFerade with chemoradiation & Phase 1 & 50 \\
\hline 17 & [35] & $\begin{array}{l}\text { Pancreatic } \\
\text { Cancer }\end{array}$ & $\begin{array}{l}\text { live-attenuated Listeria vaccine expressing mesothelin } \\
\text { (CRS-207) for advanced cancers: phase I studies of safety and } \\
\text { immune induction. }\end{array}$ & Cancer vaccine & Attenuated listeria vaccine & Phase 1 & 26 \\
\hline
\end{tabular}


Table 1. Cont.

\begin{tabular}{|c|c|c|c|c|c|c|c|}
\hline No. & Ref. & Conditions & Title & Carrier & Interventions & Phases & Enrollment \\
\hline 18 & {$[36]$} & $\begin{array}{l}\text { Pancreatic } \\
\text { Cancer }\end{array}$ & $\begin{array}{l}\text { Addition of algenpantucel-Limmunotherapy to standard } \\
\text { adjuvant therapy for pancreatic cancer: a phase } 2 \text { study. }\end{array}$ & Immunotherapy & Algenpantucel-L + gemcitabine $+5 \mathrm{FU}$ & Phase 2 & 70 \\
\hline 19 & [37] & $\begin{array}{l}\text { Pancreatic } \\
\text { Cancer }\end{array}$ & $\begin{array}{l}\text { Randomized phase III multi-institutional study of TNFerade } \\
\text { biologic with fluorouracil and radiotherapy for locally } \\
\text { advanced pancreatic cancer: final results. }\end{array}$ & Adenovirus & $\begin{array}{l}\text { AdV /TNFerade + Chemoradiation Vs } \\
\text { chemoradiation }\end{array}$ & Phase 3 & 304 \\
\hline 20 & [38] & $\begin{array}{l}\text { Pancreatic } \\
\text { Cancer }\end{array}$ & $\begin{array}{l}\text { Encapsulated cells expressing a chemotherapeutic activating } \\
\text { enzyme allow the targeting of subtoxic chemotherapy and are } \\
\text { safe and efficacious: data from two clinical trials in } \\
\text { pancreatic cancer. }\end{array}$ & Lipofectamine (Plasmid DNA) & Lipofectamine/Cyto. P450 & Phase 2 & 13 \\
\hline 21 & [39] & $\begin{array}{l}\text { Pancreatic } \\
\text { Cancer }\end{array}$ & $\begin{array}{l}\text { Gene-mediated cytotoxic immunotherapy as adjuvant to } \\
\text { surgery or chemoradiation for pancreatic adenocarcinoma. }\end{array}$ & Adenovirus & AdV/HSV thymidine kinase & Phase 1 & 24 \\
\hline 22 & [40] & $\begin{array}{l}\text { Pancreatic } \\
\text { Cancer }\end{array}$ & $\begin{array}{l}\text { RNAi therapy targeting KRAS in combination with } \\
\text { chemotherapy for locally advanced pancreatic cancer patients. }\end{array}$ & RNAi & SiG12-LODER ${ }^{\circledast}+$ gemcitabine & Phase 1/Phase 2 & 15 \\
\hline 23 & [41] & $\begin{array}{l}\text { Pancreatic } \\
\text { Cancer }\end{array}$ & $\begin{array}{l}\text { atety and survival with GVAX pancreas prime and Listeria } \\
\text { Monocytogenes-expressing mesothelin (CRS-207) boost } \\
\text { vaccines for metastatic pancreatic cancer. }\end{array}$ & Cancer vaccine & GVAX + CRS 2017 & Phase 2 & 90 \\
\hline 24 & [42] & $\begin{array}{l}\text { Pancreatic } \\
\text { Cancer }\end{array}$ & $\begin{array}{l}\text { Randomized Phase } 2 \text { Trial of the Oncolytic Virus Pelareorep } \\
\text { (Reolysin) in Upfront Treatment of Metastatic Pancreatic } \\
\text { Adenocarcinoma. }\end{array}$ & Reovirus & Reolysin + paclitaxel + carboplatin & Phase 2 & 73 \\
\hline 25 & [43] & $\begin{array}{l}\text { Pancreatic } \\
\text { Cancer }\end{array}$ & $\mathrm{AdV} /$ Theragene + Chemotherapy & Adenovirus & $\mathrm{AdV} /$ Theragene + Chemotherapy & Phase 1 & 9 \\
\hline
\end{tabular}

Table 2. Summary of clinical trials ongoing.

\begin{tabular}{|c|c|c|c|c|c|c|c|c|c|}
\hline No. & Ref. & NCT Number & Conditions & Title & Carrier & Phases & Enrollment & Study Start & Study Completion \\
\hline 1 & & NCT00415454 & Pancreatic Cancer & $\begin{array}{l}\text { Study Combining Suicide Gene Therapy with } \\
\text { Chemoradiotherapy in the Treatment of Non-Metastatic } \\
\text { Pancreatic Adenocarcinoma }\end{array}$ & Adenovirus & Phase 1 & 8 & November 2006 & N/A \\
\hline 2 & [44] & NCT01274455 & Pancreatic Cancer & Gene Therapy of Pancreatic Ductal Adenocarcinoma & Plasmid DNA & Phase 1 & 22 & December 2010 & March 2013 \\
\hline 3 & & NCT02806687 & Pancreatic Cancer & $\begin{array}{l}\text { Effect of Intratumoral Injection of Gene Therapy for Locally } \\
\text { Advanced Pancreatic Cancer }\end{array}$ & Plasmid DNA & Phase 2 & 100 & January 2017 & June 2019 \\
\hline 4 & & NCT02894944 & Pancreatic Cancer & $\begin{array}{l}\text { Clinical Trial Phase I for Theragene in Combination with } \\
\text { Chemotherapy for the Locally Advanced Pancreatic Cancer }\end{array}$ & Adenovirus & Phase 1 & 9 & August 2016 & July 2018 \\
\hline 5 & [45] & NCT00121745 & Pancreatic Cancer & $\begin{array}{l}\text { Evaluation of Safety of Rexin-G Gene Transfer for Advanced } \\
\text { Pancreatic Cancer } \\
\text { Long Term Follow-Up Study for Subjects Previously Treated }\end{array}$ & Retrovirus & Phase 1 & 12 & July 2005 & July 2007 \\
\hline 6 & & NCT03165188 & Pancreatic Cancer & $\begin{array}{l}\text { With Algenpantucel-L (HyperAcute-Pancreas) } \\
\text { Immunotherapy }\end{array}$ & Immunotherapy & Not Applicable & 500 & September 2017 & June 2031 \\
\hline 7 & & NCT01583686 & Pancreatic Cancer & $\begin{array}{l}\text { CAR T Cell Receptor Immunotherapy Targeting Mesothelin } \\
\text { for Patients With Metastatic Cancer } \\
\text { Administering Peripheral Blood Lymphocytes Transduced }\end{array}$ & CAR-T & Phase $1 /$ Phase 2 & 136 & April 2012 & December 2028 \\
\hline 8 & & NCT02830724 & Pancreatic Cancer & $\begin{array}{l}\text { With a CD70-Binding Chimeric Antigen Receptor to People } \\
\text { With CD71 Expressing Cancers }\end{array}$ & CAR-T & Phase $1 /$ Phase 2 & 113 & April 2017 & January 2028 \\
\hline 9 & & NCT00638612 & Pancreatic Cancer & $\begin{array}{l}\text { AdV-tk Therapy With Surgery and Chemoradiation for } \\
\text { Pancreas Cancer (PaTK02) }\end{array}$ & Adenovirus & Phase 1 & 27 & August 2008 & June 2015 \\
\hline 10 & & NCT02465983 & Pancreatic Cancer & $\begin{array}{l}\text { Pilot Study of Autologous T-cells in Patients With Metastatic } \\
\text { Pancreatic Cancer }\end{array}$ & CAR-T & Phase 1 & 4 & May 2015 & November 2017 \\
\hline
\end{tabular}


Table 2. Cont.

\begin{tabular}{|c|c|c|c|c|c|c|c|c|c|}
\hline No. & Ref. & NCT Number & Conditions & Title & Carrier & Phases & Enrollment & Study Start & Study Completion \\
\hline 11 & & NCT03190941 & Pancreatic Cancer & $\begin{array}{l}\text { Administering Peripheral Blood Lymphocytes Transduced } \\
\text { With a Murine T-Cell Receptor Recognizing the G12V Variant } \\
\text { of Mutated RAS in HLA-A*1102 Patients }\end{array}$ & Immunotherapy & Phase $1 /$ Phase 2 & 110 & September 2017 & June 2028 \\
\hline 12 & & NCT03225989 & Pancreatic Cancer & $\begin{array}{l}\text { Trial Investigating an Immunostimulatory Oncolytic } \\
\text { Adenovirus for Cancer }\end{array}$ & Adenovirus & Phase 1/Phase 2 & 50 & March 2018 & December 2022 \\
\hline 13 & & NCT03192462 & Pancreatic Cancer & $\begin{array}{l}\text { TAA Specific Cytotoxic T Lymphocytes in Patients With } \\
\text { Pancreatic Cancer }\end{array}$ & Immunotherapy & Phase 1/Phase 2 & 45 & January 2018 & November 2025 \\
\hline 14 & & NCT00004178 & Pancreatic Cancer & $\begin{array}{l}\text { Gene Therapy in Treating Patients With Cancer } \\
\text { Vaccine Therapy Combined With Adjuvant }\end{array}$ & Immunotherapy & Phase 1 & null & April 1998 & December 2001 \\
\hline 15 & [46] & NCT00084383 & Pancreatic Cancer & $\begin{array}{l}\text { Chemoradiotherapy in Treating Patients With Resected Stage I } \\
\text { or Stage II Adenocarcinoma (Cancer) of the Pancreas } \\
\text { Ipilimumab + / - Vaccine Therapy in Treating Patients With }\end{array}$ & Cancer vaccine & Phase 2 & 60 & January 2002 & July 2006 \\
\hline 16 & [47] & NCT00836407 & Pancreatic Cancer & $\begin{array}{l}\text { Locally Advanced, Unresectable or Metastatic Pancreatic } \\
\text { Cancer }\end{array}$ & Cancer vaccine & Phase 1 & 30 & February 2009 & July 2012 \\
\hline 17 & & NCT00305760 & Pancreatic Cancer & $\begin{array}{l}\text { Vaccine Therapy, Cyclophosphamide, and Cetuximab in } \\
\text { Treating Patients With Metastatic or Locally Advanced } \\
\text { Pancreatic Cancer }\end{array}$ & Cancer vaccine & Phase 2 & 60 & December 2005 & N/A \\
\hline 18 & & NCT02750657 & Pancreatic Cancer & $\begin{array}{l}\text { Study of Changes and Characteristics of Genes in Patients } \\
\text { With Pancreatic Cancer for Better Treatment Selection } \\
\text { Capecitabine as Second-Line Therapy in Treating Patients With }\end{array}$ & Genetic Profiling & Not Applicable & 180 & December 2015 & December 2021 \\
\hline 19 & & NCT00303927 & Pancreatic Cancer & $\begin{array}{l}\text { Stage IV Pancreatic Cancer Who Have the Thymidylate } \\
\text { Synthase Gene }\end{array}$ & Genetic Profiling & Phase 2 & 65 & December 2005 & $\mathrm{~N} / \mathrm{A}$ \\
\hline 20 & & NCT01188109 & Pancreatic Cancer & $\begin{array}{l}\text { Gemcitabine/Cisplatin for Resected Pancreas Cancer: } \\
\text { Establishing the Role of ERCC2 in Treatment Decision }\end{array}$ & Genetic Profiling & Phase 2 & 25 & July 2010 & July 2015 \\
\hline 21 & & NCT00389610 & Pancreatic Cancer & $\begin{array}{l}\text { Vaccine Therapy in Treating Patients With Pancreatic Cancer } \\
\text { That Has Been Removed by Surgery }\end{array}$ & Cancer vaccine & Phase 2 & 56 & September 2006 & December 2018 \\
\hline 22 & & NCT01394120 & Pancreatic Cancer & $\begin{array}{l}\text { Chemotherapy Selection Based on Therapeutic Targets for } \\
\text { Advanced Pancreatic Cancer }\end{array}$ & $\begin{array}{l}\text { For Targeted and } \\
\text { Tailored Treatment }\end{array}$ & Phase 2 & 60 & August 2011 & December 2013 \\
\hline 23 & & NCT00066404 & Pancreatic Cancer & $\begin{array}{l}\text { Intrapleural BG00002 in Treating Patients With Malignant } \\
\text { Pleural Mesothelioma or Malignant Pleural Effusions } \\
\text { Feasibility of Obtaining and Characterizing Circulating }\end{array}$ & Recombinant adenovirus & Phase 1 & null & April 2003 & $\mathrm{~N} / \mathrm{A}$ \\
\hline 24 & & NCT01474564 & Pancreatic Cancer & $\begin{array}{l}\text { Tumorigenic Cells in Patients With Pancreatic } \\
\text { Adenocarcinoma }\end{array}$ & Genetic Profiling & Not Applicable & 60 & November 2011 & November 2019 \\
\hline 25 & & NCT02405585 & Pancreatic Cancer & $\begin{array}{l}\text { Immunotherapy and SBRT Study in Borderline Resectable } \\
\text { Pancreatic Cancer }\end{array}$ & Immunotherapy & Phase 2 & 10 & April 2015 & $\mathrm{~N} / \mathrm{A}$ \\
\hline 26 & & NCT02705196 & Pancreatic Cancer & LOAd704 Oncolytic Virus Therapy for Pancreatic Cancer & Adenovirus & Phase 1/Phase 2 & 26 & November 2016 & August 2019 \\
\hline 27 & & NCT00669734 & Pancreatic Cancer & $\begin{array}{l}\text { Vaccine Therapy and Sargramostim in Treating Patients With } \\
\text { Pancreas Cancer That Cannot Be Removed By Surgery } \\
\text { Vaccine Therapy With or Without Cyclophosphamide in }\end{array}$ & Cancer vaccine & Phase 1 & 18 & February 2010 & $\mathrm{~N} / \mathrm{A}$ \\
\hline 28 & & NCT00727441 & Pancreatic Cancer & $\begin{array}{l}\text { Treating Patients Undergoing Chemotherapy and Radiation } \\
\text { Therapy for Stage I or Stage II Pancreatic Cancer That Can Be } \\
\text { Removed by Surgery }\end{array}$ & Cancer vaccine & Not Applicable & 87 & July 2008 & March 2018 \\
\hline 29 & & NCT00947102 & Pancreatic Cancer & $\begin{array}{l}\text { Influence of Gemcitabine Treatment on Immunological and } \\
\text { Serological Profile in Patients With Pancreatic Cancer } \\
\text { A Study of TNFerade Biologic With 5-FU and Radiation }\end{array}$ & Observation & Not Applicable & null & February 2009 & December 2011 \\
\hline 30 & & NCT00051467 & Pancreatic Cancer & $\begin{array}{l}\text { Therapy for First-Line Treatment of Unresectable Locally } \\
\text { Advanced Pancreatic Cancer }\end{array}$ & Adenovirus & Phase 3 & null & $\mathrm{N} / \mathrm{A}$ & $\mathrm{N} / \mathrm{A}$ \\
\hline 31 & & NCT03531125 & Pancreatic Cancer & Gene Expression in Resectable Pancreatic Cancer & $\begin{array}{l}\text { Procedure of Endoscopic } \\
\text { Ultrasound }\end{array}$ & Not Applicable & 10 & June 2018 & December 2019 \\
\hline 32 & & NCT00429858 & Pancreatic Cancer & $\begin{array}{l}\text { Gemcitabine and S-2 for Locally Advanced Unresectable or } \\
\text { Metastatic Pancreatic Cancer }\end{array}$ & Chemotherapy & Phase 2 & 21 & January 2007 & October 2010 \\
\hline
\end{tabular}


Table 2. Cont.

\begin{tabular}{|c|c|c|c|c|c|c|c|c|}
\hline No. Ref. & NCT Number & Conditions & Title & Carrier & Phases & Enrollment & Study Start & Study Completior \\
\hline 33 & NCT02568267 & Pancreatic Cancer & $\begin{array}{l}\text { Basket Study of Entrectinib (RXDX-101) for the Treatment of } \\
\text { Patients With Solid Tumors Harboring NTRK } 1 / 2 / 3 \text { (Trk } \\
\text { A/B/C), ROS2, or ALK Gene Rearrangements (Fusions) }\end{array}$ & Genetic Profiling & Phase 2 & 300 & November 2015 & October 2020 \\
\hline 34 & NCT00159471 & Pancreatic Cancer & $\begin{array}{l}\text { Genes as Predictors of Response to Gemcitabine, Docetaxel, } \\
\text { and Capecitabine (GTX) in Metastatic or Unresectable } \\
\text { Pancreatic Cancer. }\end{array}$ & Genetic Profiling & Not Applicable & 1 & February 2005 & July 2006 \\
\hline 35 & NCT00386399 & Pancreatic Cancer & $\begin{array}{l}\text { Study of Mitomycin-C in Patients With Advanced or Recurrent } \\
\text { Pancreatic Cancer With Mutated BRCA3 Gene }\end{array}$ & Genetic Profiling & Phase 2 & 0 & October 2006 & February 2008 \\
\hline 36 & NCT01836432 & Pancreatic Cancer & $\begin{array}{l}\text { Immunotherapy Study in Borderline Resectable or Locally } \\
\text { Advanced Unresectable Pancreatic Cancer }\end{array}$ & Immunotherapy & Phase 3 & 302 & May 2013 & June 2017 \\
\hline 37 & NCT00255827 & Pancreatic Cancer & Vaccine Treatment for Surgically Resected Pancreatic Cancer & Cancer vaccine & Phase $1 /$ Phase 2 & 7 & November 2005 & September 2007 \\
\hline 38 & NCT01938716 & Pancreatic Cancer & $\begin{array}{l}\text { Gemcitabine Pharmacokinetics After Preoperative } \\
\text { Chemoradiation Therapy } \\
\text { A Study of Multiple Immunotherapy-Based Treatment }\end{array}$ & Chemotherapy & Not Applicable & 40 & March 2012 & March 2019 \\
\hline 39 & NCT03193190 & Pancreatic Cancer & $\begin{array}{l}\text { Combinations in Participants With Metastatic Pancreatic } \\
\text { Ductal Adenocarcinoma (Morpheus-Pancreatic Cancer) }\end{array}$ & Immunotherapy & Phase $1 /$ Phase 2 & 185 & July 2017 & September 2020 \\
\hline 40 & NCT00089024 & Pancreatic Cancer & $\begin{array}{l}\text { Combination Chemotherapy, and Radiation Therapy in } \\
\text { Treating Patients With Locally Advanced Pancreatic Cancer } \\
\text { Targeted Therapy Directed by Genetic Testing in Treating }\end{array}$ & Chemotherapy & Phase 2 & 50 & February 2004 & $\mathrm{~N} / \mathrm{A}$ \\
\hline 41 & NCT02465060 & Pancreatic Cancer & $\begin{array}{l}\text { Patients With Advanced Refractory Solid Tumors, } \\
\text { Lymphomas, or Multiple Myeloma (The MATCH Screening } \\
\text { Trial) }\end{array}$ & Genetic Profiling & Phase 2 & 6452 & August 2015 & $\mathrm{~N} / \mathrm{A}$ \\
\hline 42 & NCT01191684 & Pancreatic Cancer & $\begin{array}{l}\text { Vaccine Therapy in Treating Patients With Colorectal, Stomach, } \\
\text { or Pancreatic Cancer }\end{array}$ & Cancer vaccine & Phase 1 & 12 & October 2011 & August 2013 \\
\hline 43 & NCT01088789 & Pancreatic Cancer & A Trial of Boost Vaccinations of Pancreatic Tumor Cell Vaccine & Plasmid DNA & Phase 2 & 72 & April 2010 & April 2023 \\
\hline 44 & NCT02514421 & Pancreatic Cancer & $\begin{array}{l}\text { Evaluation of Safety and Efficacy of Electrochemotherapy in } \\
\text { the Treatment of Pancreatic Adenocarcinoma } \\
\text { Patient Derived Cancer Cell Lines in Identifying Molecular }\end{array}$ & Device of Electroporation & Not Applicable & 24 & July 2015 & July 2017 \\
\hline 45 & NCT02414100 & Pancreatic Cancer & $\begin{array}{l}\text { Changes in Patients With Previously Untreated Pancreatic } \\
\text { Cancer Receiving Gemcitabine Hydrochloride-Based } \\
\text { Chemotherapy }\end{array}$ & Genetic Profiling & Not Applicable & 0 & December 2013 & December 2016 \\
\hline $\begin{array}{l}46 \\
47\end{array}$ & NCT00936104 & Pancreatic Cancer & Side Population in Pancreatic Ductal Adenocarcinoma (PDAC) & & Not Applicable & 20 & August 2008 & July 2012 \\
\hline $\begin{array}{l}47 \\
48\end{array}$ & NCT03302637 & Pancreatic Cancer & $\begin{array}{l}\text { Oral Microbiome and Pancreatic Cancer } \\
\text { Study of A166 in Patients With Relapsed/Refractory Cancers }\end{array}$ & Genetic Profiling & Not Applicable & 732 & December 1992 & December 2010 \\
\hline 48 & NCT03602079 & Pancreatic Cancer & $\begin{array}{l}\text { Expressing HER2 Antigen or Having Amplified HER3 Gene } \\
\text { Liposomal Irinotecan, Fluorouracil, Leucovorin Calcium, and }\end{array}$ & Genetic Profiling & Phase 1 / Phase 2 & 82 & July 2018 & May 2021 \\
\hline 49 & NCT03337087 & Pancreatic Cancer & $\begin{array}{l}\text { Rucaparib in Treating Patients With Metastatic Pancreatic, } \\
\text { Colorectal, Gastroesophageal, or Biliary Cancer }\end{array}$ & Chemotherapy & Phase 1/Phase 2 & 110 & August 2018 & December 2022 \\
\hline 50 & NCT00128622 & Pancreatic Cancer & $\begin{array}{l}\text { Denileukin Diftitox Followed by Vaccine Therapy in Treating } \\
\text { Patients With Metastatic Cancer }\end{array}$ & Cancer vaccine & Phase 1 & 24 & September 2005 & May 2009 \\
\hline 51 & NCT02592395 & Pancreatic Cancer & $\begin{array}{l}\text { Study of FOLFIRINOX Electrochemotherapy in the Treatment } \\
\text { of Pancreatic Adenocarcinoma }\end{array}$ & Device of Electroporation & Phase 1 & 0 & October 2015 & October 2017 \\
\hline 52 & NCT02432963 & Pancreatic Cancer & $\begin{array}{l}\text { Vaccine Therapy and Pembrolizumab in Treating Patients With } \\
\text { Solid Tumors That Have Failed Prior Therapy }\end{array}$ & Cancer vaccine & Phase 1 & 19 & November 2015 & February 2019 \\
\hline 53 & NCT00959946 & Pancreatic Cancer & $\begin{array}{l}\text { Study Of Bosutinib With Capecitabine In Solid Tumors And } \\
\text { Locally Advanced Or Metastatic Breast Cancer } \\
\text { Genotype-guided Dosing of mFOLFIRINOX Chemotherapy in }\end{array}$ & Chemotherapy & Phase 1/Phase 2 & 32 & September 2009 & March 2011 \\
\hline 54 & NCT01643499 & Pancreatic Cancer & $\begin{array}{l}\text { Patients With Previously Untreated Advanced Gastrointestinal } \\
\text { Malignancies }\end{array}$ & Genetic Profiling & Phase 1 & 79 & March 2012 & August 2020 \\
\hline 55 & NCT02576665 & Pancreatic Cancer & $\begin{array}{l}\text { A Study of Toca 511, a Retroviral Replicating Vector, } \\
\text { Combined With Toca FC in Patients With Solid Tumors or } \\
\text { Lymphoma (Toca 7) }\end{array}$ & Retrovirus & Phase 1 & 30 & July 2016 & November 2019 \\
\hline
\end{tabular}


Table 2. Cont.

\begin{tabular}{|c|c|c|c|c|c|c|c|c|}
\hline No. Ref. & NCT Number & Conditions & Title & Carrier & Phases & Enrollment & Study Start & Study Completion \\
\hline 56 & NCT00711997 & Pancreatic Cancer & $\begin{array}{l}\text { Phase 1/2a DTA-H19 in Patients With Unresectable } \\
\text { Pancreatic Cancer }\end{array}$ & Plasmid DNA & Phase 1/Phase 2 & 9 & August 2009 & December 2010 \\
\hline 57 & NCT02239861 & Pancreatic Cancer & TAA-Specific CTLS for Solid Tumors (TACTASOM) & Immunotherapy & Phase 1 & 16 & April 2015 & December 2018 \\
\hline 58 & NCT03281382 & $\begin{array}{c}\text { Metastatic } \\
\text { Pancreatic Cancer }\end{array}$ & $\begin{array}{l}\text { Phase } 1 \text { Trial of Interleukin } 13 \text { Gene Therapy for Metastatic } \\
\text { Pancreatic Cancer }\end{array}$ & Adenovirus & Phase 1 & 9 & July 2017 & June 2021 \\
\hline 59 & NCT02340117 & $\begin{array}{c}\text { Metastatic } \\
\text { Pancreatic Cancer }\end{array}$ & $\begin{array}{l}\text { Study of Combined SGT-54 Plus Gemcitabine/Nab-Paclitaxel } \\
\text { for Metastatic Pancreatic Cancer }\end{array}$ & Immunotherapy & Phase 2 & 28 & January 2015 & December 2020 \\
\hline 60 & NCT00868114 & $\begin{array}{c}\text { Metastatic } \\
\text { Pancreatic Cancer }\end{array}$ & $\begin{array}{l}\text { Direct Tumor Injection KLH-Pulsed Dendritic Cells in } \\
\text { Unresectable Pancreatic Cancer }\end{array}$ & Cell & Phase 2 & 35 & July 2006 & December 2015 \\
\hline 61 & NCT01437007 & $\begin{array}{c}\text { Metastatic } \\
\text { Pancreatic Cancer }\end{array}$ & TKM 080302 for Primary or Secondary Liver Cancer & RNAi & Phase 1 & 1 & August 2011 & June 2012 \\
\hline 62 & NCT02416466 & $\begin{array}{c}\text { Metastatic } \\
\text { Pancreatic Cancer }\end{array}$ & $\begin{array}{l}\text { CAR-T Hepatic Artery Infusions and Sir-Spheres for Liver } \\
\text { Metastases }\end{array}$ & CAR-T & Phase 1 & 8 & April 2015 & January 2019 \\
\hline 63 & NCT01116791 & $\begin{array}{l}\text { Peritoneal } \\
\text { Carcinomatosis }\end{array}$ & $\begin{array}{l}\text { Cytoreductive Surgery (CRS) Plus Hyperthermic } \\
\text { Intraoperative Peritoneal Chemotherapy(HIPC) With Cisplatin } \\
\text { to Treat Peritoneal Carcinomatosis From Upper } \\
\text { Gastrointestinal Cancer }\end{array}$ & $\begin{array}{l}\text { Procedure of } \\
\text { Cytoreductive Surgery } \\
\text { plus Hyperthermic } \\
\text { Intraoperative Peritoneal } \\
\text { Chemotherapy }\end{array}$ & Phase 2 & 34 & July 2010 & December 2015 \\
\hline 64 & NCT02315625 & $\begin{array}{l}\text { Neuroendocrine } \\
\text { Tumors of the } \\
\text { Pancreas }\end{array}$ & $\begin{array}{l}\text { Study of Mutation-Targeted Therapy With Sunitinib or } \\
\text { Everolimus in People With Advanced Low- or } \\
\text { Intermediate-Grade Neuroendocrine Tumors of the } \\
\text { Gastrointestinal Tract and Pancreas With or Without } \\
\text { Cytoreductive Surgery }\end{array}$ & Genetic Profiling & Phase 2 & 120 & April 2015 & December 2025 \\
\hline 65 & NCT00444444 & Pancreatitis & $\begin{array}{l}\text { Genetic Analysis for Predicting of Relapse During Steroid } \\
\text { Treatment for Autoimmune Pancreatitis (AIP) }\end{array}$ & & & 40 & February 2002 & June 2007 \\
\hline
\end{tabular}


Other preclinical studies, however, demonstrated the relationship of chemotherapy and gene expression [48]. A study showing gemcitabine-mediated tumor regression and p53-dependent gene expression increased the possibility that targeting the Bax-dependent cell death pathway, rather than the PUMA pathway, might result in significantly improved patient outcomes and prognosis in pancreatic cancer [49]. Intravenous administration of Rexin- $G^{\mathrm{TM}}$, a nonreplicative pathology-targeted retroviral vector bearing a cytocidal cyclin G1 construct, exhibited a good safety and efficacy profile in a phase I/II trial of gemcitabine-resistant pancreatic cancer [30]. Intratumoral administration of CYL-02, a nonviral gene therapy product, using endoscopic ultrasound was found to be safe in a phase I trial including 22 patients who were concomitantly treated with gemcitabine [44]. Conversely, RNAi therapy targeting KRAS in combination with chemotherapy showed efficacy in treating locally advanced pancreatic cancer patients [40], whereas the G-protein-coupled receptor family C, member 5, group A gene was upregulated in PaCa cells, which led to enhanced drug resistance in PaCa cells [50]. These data can aid in the implementation of personalized therapy for improved outcomes in patients with pancreatic cancer. In addition to pancreatic malignancies, ongoing studies are aimed to establish effective gene therapies for pancreatitis, pancreatic pain, and diabetes mellitus. Based on the several completed (Table 1) and ongoing clinical trials [19-47] (Table 2), gene therapy offers a promising avenue as a safe and efficient approach [51].

Various techniques used for gene therapy, including synthetic and viral vectors, molecular tools, such as interference RNA, and genome editing methods, showed promising results in filling the gap between experimental models of cancer and clinical trials [10,52], therefore in this review, the methods of gene delivery into the pancreas used in studies are also summarized (Table 3). This review summarizes the current landscape of completed and ongoing studies on these diseases for both the physicians and the researchers. 
Table 3. Gene delivery methods used in clinical and pre-clinical stages.

\begin{tabular}{|c|c|c|c|c|}
\hline Gene Transfer Methods & Functional Component & Targeted Genes & Features & Features \\
\hline Viral Vectors & & \multirow{19}{*}{$\begin{array}{l}\text { Tumor suppressor genes, Pro-apoptotic } \\
\text { genes, Suicide genes, siRNA, miRNA, }\end{array}$} & & \\
\hline Oncoretrovirus & RNA & & High efficiency & Random integration, low titer \\
\hline Lentivirus & RNA & & High efficiency, sustained gene expression & Random integration, low titer \\
\hline Foamy virus & RNA & & High efficiency, sustained gene expression & Random integration, low titer \\
\hline Adenovirus & Double stranded DNA & & $\begin{array}{l}\text { High efficiency, sustained gene expression, infect } \\
\text { non-dividing cells }\end{array}$ & Host innate immune response \\
\hline Adeno-associated virus & Single stranded DNA & & $\begin{array}{l}\text { No pathogenic, sustained gene expression, infect to } \\
\text { non-dividing cells }\end{array}$ & $\begin{array}{l}\text { Integration may occur, small capacity } \\
\text { of transgene, low titer }\end{array}$ \\
\hline Herpes simplex virus & Double stranded DNA & & No integration, sustained gene expression & Low transduction efficiency \\
\hline Non-viral Vectors (Chemicals) & & & & \\
\hline Lipids & Cationic lipids & & High efficiency in vitro, ease to prepare & Low efficiency in vivo, acute immune \\
\hline Polymers & \multirow{2}{*}{$\begin{array}{l}\text { Cationic polymers } \\
\text { Natural or chemically modified proteins } \\
\text { in cationic nature }\end{array}$} & & \multirow{3}{*}{$\begin{array}{l}\text { Highly effective in vitro, ease to prepare } \\
\text { Highly effective in vitro, less toxic, can be } \\
\text { target specific } \\
\text { Highly effective in vitro, less toxic, can be } \\
\text { target specific }\end{array}$} & Toxic to cells, acute immune response \\
\hline Proteins & & & & Low activity in vivo \\
\hline Peptides & Lysine or arginine residues in peptides & & & Low activity in vivo \\
\hline \multicolumn{4}{|l|}{$\begin{array}{l}\text { Non-viral Vectors (Physical } \\
\text { Methods) }\end{array}$} & \\
\hline Needle injection & Mechanic force & & Simple & $\begin{array}{l}\text { Low efficiency, expression limited to } \\
\text { needle track }\end{array}$ \\
\hline Gene gun & Pressure & & Good efficiency & $\begin{array}{l}\text { Limited to target area, need surgical } \\
\text { procedure for internal organ }\end{array}$ \\
\hline Electroporation & Electric pulse & & High efficiency & $\begin{array}{l}\text { Tissue damage, limited target area, } \\
\text { need surgical procedure for } \\
\text { internal organ }\end{array}$ \\
\hline Sonoporation & Ultrasound & & Site specific & $\begin{array}{l}\text { Low efficiency, tissue damage } \\
\text { Low efficiency, limited target area, }\end{array}$ \\
\hline Magnetofection & Magnetic field & & Site specific & $\begin{array}{l}\text { need surgical procedure for } \\
\text { internal organ }\end{array}$ \\
\hline Hydrodynamic delivery & Hydrodynamic pressure & & Simple, high efficiency, site specific & $\begin{array}{l}\text { Need catheter insertion technique in } \\
\text { large animals }\end{array}$ \\
\hline Immunotherapy & Cytokines & & Require ex vivo cell culture & \\
\hline Adoptive Immunotherapy & CAR-T & & Require ex vivo cell culture & \\
\hline Vaccination & Antigen-pulsed dendritic cells & & Intravenous or subcutaneous or local administration & \\
\hline
\end{tabular}




\section{Pancreatic Cancer}

The latest developments in pancreatic carcinoma gene therapy include gene-based tumor cell sensitization to chemotherapy, vaccination, and adoptive immunotherapy (chimeric antigen receptor T-cell [CAR-T] therapy). Furthermore, oncolytic virus therapies, including oncolytic adenoviruses, herpes virus, parvovirus, and reovirus are currently in development [10].

Preclinical studies showed promising results in the efficacy of gene therapy. For example, the Lister strain of vaccinia virus armed with the endostatin-angiostatin fusion gene exhibited therapeutic efficacy for potential pancreatic cancer [53], whereas the inhibition of miR-21 led to the inhibition of pancreatic cancer tumor growth both in vitro and in vivo [54]. Additionally, introduction of decoy hyper-binding sites to sequester and suppress the entry of oncogenic HMGA1 into the nucleus of pancreatic cancer cells by replication-defective adenovirus serotype 5 virus achieved inhibition of cancer cell growth [55].

Virus vectors used in these gene therapy studies include adeno-associated virus (AAV) vectors with capsids that are modified and optimized by site-directed mutagenesis to improve the transduction efficiency in the pancreatic tissue, especially in pancreatic cancer cells [56]. Studies using oncolytic virus vectors utilize hexon modification to improve the activity of the oncolytic adenovirus vectors targeting the TGFBR to enable replication in tumor stromal cells as well [57]. Targeted herpes simplex virus (HSV)-1 (HSV-1) whose expression is regulated by the cellular B-myb promoter in an experimental model of pancreatic tumor resulted in an effective reduction in tumor growth [58]. However, in a phase II clinical trial, the progression-free survival rate was not improved in patients with metastatic pancreatic cancer who were treated with chemotherapy in combination with the oncolytic virus pelareorep, which causes oncolysis in pancreatic cells by activating Ras [42]. On the other hand, oncosuppressive parvovirus $\mathrm{H} 1$ increased sensitivity to chemotherapy and inhibited the activation of the NFKB and the Akt/PI3K pathways in patients with pancreatic peritoneal carcinomatosis [59].

Recent advances in the safety and efficacy of the CRISPR/Cas9 genome editing method [60] led to several studies that investigated its utility in pancreatic cancer. For example, retrograde pancreatic ductal injection of adenoviral-Cre and lentiviral-Cre vectors were utilized to develop in vivo models of pancreatic cancer [61]; this technique can significantly contribute to the establishment of novel therapies for pancreatic cancer.

Additional strategies utilizing gene targeting methods include cell therapies, such as T-cell programming [62], immunotherapy, and CAR-T [63,64]; induction of T-cell immunity to cancer antigens, such as mesothelin by GVAX pancreas; and granulocyte-macrophage colony-stimulating factor-secreting allogeneic pancreatic tumor cells for pancreatic cancer patients with metastatic lesions [41].

These studies are likely to change the clinical practice and approaches to PDAC management, as they represent a major advancement not only for PDAC, but also for the broader field of gene-based molecular treatment of cancer.

\section{Pancreatitis}

Pancreatitis, inflammation of the pancreas, can be classified into acute and chronic forms. Inflammation can be due to various factors, including alcohol, fatty food, gallstones, high serum calcium concentrations caused by the hyperparathyroidism, abdominal injury, chemotherapeutic agents, and pancreatic neoplasms. The etiological factor activates the pancreatic digestive enzymes in the pancreas itself instead of the small intestine. Abdominal pain, back pain, fever, nausea, and diarrhea are the major symptoms of pancreatitis, which may lead to abscess formation, infection, pseudocysts, multiple organ failure, malnutrition, diabetes mellitus, and pancreatic cancer.

Among the various etiologies, associations of genetic mutations with acute recurrent and chronic pancreatitis in children were reported [65]. And gene therapy was studied in patients with genetic lipoprotein lipase deficiency-induced pancreatitis [66]. Alipogene tiparvovec was tested in 19 patients with lipoprotein lipase deficiency, and the retrospective analysis of follow-up for up to 6 years after a single treatment demonstrated the association of alipogene tiparvovec with lower frequency and 
severity of pancreatitis events [66]. In addition, the genetic association of recurrent autoimmune pancreatitis with resistance to steroid therapy is currently evaluated with NCT00444444. In this study, high-resolution typing for HLA with sequence-based typing is utilized to determine whether certain alleles or haplotypes of major histocompatibility complex gene are associated with autoimmune pancreatitis. Further analyses and trials will be conducted with the genomic information of this disease entity.

\section{Pancreatic Pain}

Abdominal pain is a major symptom associated with pancreatic diseases, and improvement of pain in acute pancreatitis is associated with the resolution of inflammation; however, pain related to pancreatic cancer and chronic pancreatitis persists and recurs and is therefore difficult to manage [67]. The currently available management methods include analgesics, antioxidant micronutrients, drugs interfering with neural transmission, pancreatic enzymes, celiac plexus blockade, and surgery [67]. As the severity of pain is associated with a decrease in quality of life, loss of appetite, and longer and frequent hospitalization and given that the development of various chemotherapeutic options for pancreatic cancer have led to a longer lifespan, it is essential to develop novel therapeutic options to manage pancreatic pain. Recent preclinical studies revealed that several neuroimmune and neuroplastic mechanisms, including infiltration of inflammatory cells, neural edema, perineural disruption, and neural hypertrophy, are involved as the underlying mechanisms of chronic pancreatitis pain [67]. Furthermore, a recent study reported the contribution of the neuronal transforming growth factor beta (TGF- $\beta$ ) signaling mediated via neuronal SMAD3 to the development of pancreatic pain in an animal model [68].

Based on these findings, a replication-defective herpes viral vector (HSV-1) construct encoding the human preproenkephalin (ENK) gene (HSV-ENK) was tested in a preclinical in vivo study $[69,70]$. HSV-ENK was applied directly to the surface of the pancreas in rats with dibutyltin dichloride-induced pancreatitis rats, and their spontaneous behavioral activity was monitored. Compared with the controls, HSV-ENK-treated rats showed significantly increased expression of ENK in the pancreas, improved activity, and normalized FOS staining, indicating reduced neuronal activity [69]. Similar results were shown in rat models of high-fat- and alcohol liquid diet-induced pancreatitis [70]. Importantly, both studies showed the preservation of the acinar cells and amelioration of the inflammation, suggesting that this method might be potentially effective for not only pain control, but also pancreatic function in chronic pancreatitis.

The overexpression of TGF- $\beta$ in mice and rats was associated with sensory neuron hyperexcitability, SMAD3 activation, and increase in nociception. As chronic pancreatitis leads to pancreatic fibrosis and that the TGF- $\beta$ signaling pathway was shown to be associated with fibrosis, this signaling pathway can be utilized as a therapeutic target to reduce pain and fibrosis in patients with chronic pancreatitis [68]. Given that the currently available treatment options are not sufficient to manage the severe pancreatic pain, development of new strategies are sorely needed.

\section{Diabetes Mellitus}

Diabetes mellitus is characterized by hyperglycemia arising from dysregulation of insulin and categorized into type 1 , type 2 , and gestational diabetes. The treatment approaches in diabetes depend on the type. Insulin replacement is used to treat patients with type 1 diabetes, which is caused by the impairment of pancreatic beta cells producing insulin. Type 2 diabetes is caused by an insufficient insulin level or hyposensitivity of the cells in the body to insulin, whereas gestational diabetes occurs in females during pregnancy and requires careful management to avoid complications in the child. Since chronic hyperglycemia leads dysfunction in various organs, including the vessels, heart, kidneys, retina, and the nervous system, careful management of blood glucose levels is necessary.

Genetic predisposition to diabetes has been reported in several studies. For example, mutation of neuronal differentiation 1, a basic helix-loop-helix transcription factor involved in the development of pancreas, can be found in patients with neonatal diabetes, as well as those with type 2 diabetes 
mellitus [71]. Gene therapy approaches currently explored for diabetes mellitus include insulin gene therapy for type 1 diabetes mellitus, in which insulin expression in non-beta cells of the pancreas with hepatocytes emerged as the primary therapeutic target [72]; fibroblast growth factor 21 (FGF21) gene therapy, which has showed promising results in a mouse model of metabolic disease [73]; GLP-1 gene therapy, which improved insulin sensitivity and reduced abdominal and hepatic fat associated with obesity-induced diabetes mellitus and altered adipokine profiles [74]; and in vivo reprogramming of pancreatic ductal cells by intraductal delivery of an adenoviral vector expressing transcription factors essential for beta cell function, which resulted in the induction of beta-like cells and correction of hyperglycemia [75]. The combination of gene and cell therapy has also been reported to induce insulin-producing cells from the hepatocytes of newborn rats. In that study, analysis of miRNA expression the differentiation of hepatocytes to insulin-producing cells was associated with the BMP/Smad signaling pathway rather than the Wnt/ $\beta$-catenin signaling pathway [76]. More recently, transfection of Sarco-ER $\mathrm{Ca}^{2+}$-ATPase $2 \mathrm{~b}$ gene in adipose mesenchymal stem cells exhibited a significant therapeutic effect in a mouse model of type 1 diabetes [77]. Recent reports also showed the effect of FGF21 gene therapy on a high-fat-diet mouse model where treatment was associated with significant reductions in body weight, adipose tissue hypertrophy, insulin resistance, hepatic steatosis, inflammation, and fibrotic changes [78]. That study used AAV vectors to mediate long-term and sustained protein production using liver-specific promoters, which resulted in sustained levels of circulating FGF21 for up to 1 year. Interestingly, FGF21 overexpression in normal mice fed with standard diet was also associated with the prevention of weight gain and insulin resistance related to aging [78]. These preclinical studies illustrate the promising results of gene therapy for diabetes by targeting the pancreas.

\section{Delivery Methods for Pancreatic Gene Therapy}

The various methods for gene delivery used in clinical and preclinical studies of the pancreas can be classified into ex vivo and in vivo methods [79]. Ex vivo gene transfer involves genetic modification of the cells harvested from the patients or experimental animals, which are then reintroduced to the patients or the animals. In vivo gene delivery methods can be further categorized into systemic administration and in situ delivery. The strategies of gene therapy for the pancreas are summarized in Figure 1.

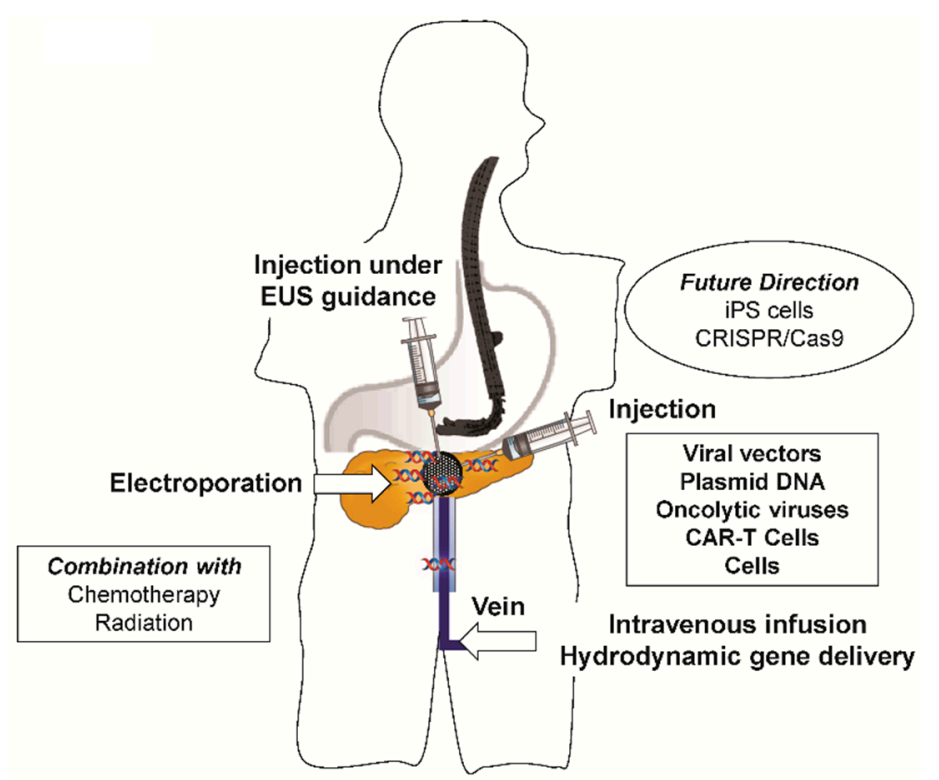

Figure 1. Schematic summary of the strategies of gene therapy for the pancreas. EUS, endoscopic ultrasound; iPS cells, inducible pluripotent stem cells; CRISPR/Cas9, clustered regularly interspaced short palindromic repeats/CRISPR associated protein 9; CAR-T, chimeric antigen receptor-T cell; DNA, deoxyribonucleic acid. 
Viral vectors used in studies thus far include oncoretrovirus, lentivirus, foamy virus, adenovirus, AAV, and HSV (Tables 1 and 2). The features of these viral vectors are summarized in Table 3. Among these, the adenovirus and AAV vectors are commonly used as gene carriers in clinical trials (Tables 1 and 2). For example, an ongoing phase III trial (NCT00051467) is assessing whether TNFerade, a replication-deficient adenovirus vector that delivers tumor necrosis factor-alpha to tumor cells and is controlled by a chemoradiation-inducible promoter, in combination with 5-fluorouracil and radiation therapy will enhance their anti-tumor effect as first-line treatment of unresectable locally advanced pancreatic cancer.

For in vivo gene delivery, non-viral vector-based methods, including plasmid DNA injection, have also been utilized to deliver genes into target sites in the pancreas in clinical trials (Tables 1 and 2), whereas other non-viral vector-based methods, including chemical compound carriers and physical methods of gene delivery, have been tested in preclinical trials, as described earlier. Among the chemical approaches are cationic lipids, polymers, and chemically modified proteins, whereas simple needle injection, gene gun, electroporation, sonoporation, magnetofection, and hydrodynamic gene delivery are major methods of delivery by physical methods. The features of the gene delivery methods are also summarized in Table 3. In addition to the currently ongoing clinical trials assessing plasmid gene injection, as well as viral vectors, a study (NCT02514421) is evaluating the efficacy and safety of electrochemotherapy using electroporation for the treatment of pancreatic cancer. Overall, these studies demonstrated the significance of the physical approach in clinical application. Furthermore, image-based guidance is essential for site-specific gene delivery in vivo, especially in the pancreas. Therefore, combination of gene delivery approaches with endoscopic ultrasound has been tested their safe and effective in situ delivery in pancreatic cancer $[20,23,25,27,31,33,34,37]$ (Tables 1 and 2). This technique has been successfully used in a clinic setting to block sympathetic innervation for the management of chronic pancreatic pain, wherein endoscopic ultrasound is used to inject neurolytic solutions to celiac plexus for neurolysis; this technique can be used to deliver genes. In the currently ongoing clinical trials, this technique has been combined with intratumoral injection of viral vectors, plasmids, and immunologically modified cells, among others (Table 3).

A recent preclinical study by Kamimura et al. reported pancreas-targeted and specific hydrodynamic gene delivery through the superior mesenteric vein into the pancreas and demonstrated its efficacy and safety using naked DNA [80]. Although the insertion of the catheter is essential, this clinically well-stablished physical and organ-specific gene delivery method can be used for both gene therapy studies and the establishment of pancreatic cancer animal models, in which oncogenic genes can be delivered to the pancreas to study various pancreatic tumor types for the development of appropriate therapeutic strategies. Another approach of siRNA delivery is ionizable low-molecular-weight polymeric nanoparticles, which has been demonstrated in nonhuman primates [81]. That study showing endothelial gene silencing in multiple nonhuman primate organs using systemically administered siRNA nanoparticles highlights the potential of this approach for the treatment of disease in humans. Recent report showed that the autophagy is related to pancreatic cancer development and the disruption of the autophagy related gene and reduced autophagy related protein level contributed to inhibit the tumorigenesis. Therefore, the gene therapy managing the autophagy might be the additional option and the nucleic acids to control the gene expression is promising strategy [82]. Further efforts are essential to develop and improve appropriate gene delivery methods for pancreatic diseases.

\section{Clinical Trials}

Building on preclinical studies, several clinical trials have been conducted to evaluate gene therapy in pancreatic diseases, especially pancreatic cancer [19-47]. A summary of these studies can be found in Table 1. Adenoviruses, plasmids, and synthetic vectors were used to deliver interleukin and suicide genes for therapeutic purposes. These genes were delivered by in situ injection with endoscopic ultrasound, intradermal or subcutaneous vaccination, or oncolytic virus injection. In addition, 
majority of these trials were coupled with chemotherapy or radiochemotherapy. Only one of these trials was a phase III study, and the remaining studies were phase I or II. The phase III trial was a randomized multi-institutional study conducted to assess the efficacy of TNFerade as a novel gene transfer method to deliver tumor necrosis factor-alpha to tumor cells, in combination with 5-fluorouracil and radiotherapy for locally advanced pancreatic cancer. TNFerade was injected intratumorally before the first fraction of radiotherapy using percutaneous transabdominal or endoscopic ultrasound [37]. Although the anti-tumor effect of TNFerade was not significant, the approach was determined to be safe and confirmed to be usable in combination with the clinically well-established methods.

A summary of the currently ongoing trials can be found in Table 2 [51]. These studies include gene therapy approaches using interleukin 13 and suicide genes; gene vaccination using plasmid DNA; and oncolytic viral gene therapy for pancreatic cancer, metastatic pancreatic cancer, pancreatic neuroendocrine tumor, and pancreatitis. In addition, cell therapies, including CAR-T for adoptive immunotherapy, are being evaluated in clinical trials. This system is considered as an adoptive active immunotherapy and autologous CD8 positive T cells are extracted from the patients and modified ex vivo to recognize and kill the cancer cells expressing the tumor antigen. There are more than 20 clinical trials still recruiting the candidate for the trials and newer trials will start continuously to develop the safe and effective gene therapy for the pancreatic diseases.

In these clinical trials on pancreatic diseases, standard methods of systemic administration and in situ gene transfer by infusion or electroporation, and site-specific administration using endoscopic ultrasound techniques are combined with various chemotherapies, including gemcitabine, cyclophosphamide, fludarabine, capecitabine, cisplatin, nab-paclitaxel, docetaxel, fluorouracil, sunitinib, and everolimus. For example, the clinical trial of NCT01274455 showed the safety of administration of non-viral gene product of CYL-02, which encodes mouse somatostatin receptor subtype 2 and a fusion gene of deoxycytidine kinase and monophosphate kinase, which could sensitize the cancer cells to gemcitabine [44] and the clinical trial of NCT00836407 evaluated the effect of granulocyte-macrophage colony stimulating factor gene-delivered pancreatic tumor cells with the ipilimumab [47]. This macrophage colony stimulating factor cold also been used for the cancer vaccine therapy [46]. Majority of these trials are phase I or II, and further enrollment and assessment of the safety and efficacy is essential. However, pancreas-specific gene targeting can be achieved with the development of delivery methods, vectors, and clinical techniques. In addition, genome information-based precision medicine with mutation-targeted therapy is being tested in a phase II trial on advanced low- or intermediate-grade neuroendocrine tumors of the pancreas (NCT02315625).

\section{Conclusions and Future Directions}

Pancreas is a key organ for digestion and endocrine function. Among the diseases affecting the pancreas, pancreatic cancer is a leading cause of cancer-related deaths worldwide. With the development of studies on gene therapy, various clinical trials are ongoing and showing the promising results, as well as in the basic preclinical researches for the gene delivery. With recent advances in promising technologies, such as the generation of induced pluripotent stem cells and gene editing by CRISPR/Cas9, development of delivery systems, carriers, and methods is essential. The findings of these studies and new methodologies that are developed for gene therapy can also be useful for currently untreatable pancreatic diseases and further studies to combine these methodologies will encourage new endeavor for the novel therapeutic options. For example, as in vivo gene editing based on CRISPR/Cas9, short-term transgene expression may be preferred, in order to prevent off-target effects, therefore, transient gene expression mediated by non-viral vector-based delivery methods might be advantageous over gene editing. While further investigation is needed to improve efficacy, with the advanced gene delivery methods armed with personal genomic information, these methods can be tailored to each patient based on specific biomarkers, which should ultimately improve prognosis and extend the life expectancy of the patients with pancreatic diseases. 
Funding: The research in the authors' laboratories has been supported in part by Grant-in-Aid for Scientific Research from the Japanese Society for the Promotion of Sciences 22890064, 23790595, 26860354, and 17K09408 to Kamimura K, 16K19333 to Yokoo T; Takara Bio Award from JSGT to Kamimura K; and Research grant from Pancreas Research Foundation of Japan to Kamimura K.

Conflicts of Interest: The authors declare that they have no conflict of interest.

\section{References}

1. Susan, S. Gray's Anatomy, the Anatomical Basis of Clinical Practice London, 41st ed.; Stringer, M.D., Ed.; Churchill Livingstone: London, UK, 2015.

2. Saad, A.M.; Turk, T.; Al-Husseini, M.J.; Abdel-Rahman, O. Trends in pancreatic adenocarcinoma incidence and mortality in the United States in the last four decades; a SEER-based study. BMC Cancer 2018, 18, 688. [CrossRef] [PubMed]

3. Outani, H.; Akita, H.; Nakai, T.; Takada, R.; Imura, Y.; Tanaka, T.; Tamiya, H.; Oshima, K.; Takahashi, H.; Ohkawa, K.; et al. Clinical features and prognosis of patients With the bone metastasis of pancreatic cancer: A single-institutional cohort study. Pancreas 2018, 47, e43-e46. [CrossRef] [PubMed]

4. Mueller, A.M.; Meier, C.R.; Jick, S.S.; Schneider, C. The potential of glycemic control and body weight change as early markers for pancreatic cancer in patients with long-standing diabetes mellitus: A case-control study. Pancreas 2018, 47, 807-815. [CrossRef] [PubMed]

5. Danai, L.V.; Babic, A.; Rosenthal, M.H.; Dennstedt, E.A.; Muir, A.; Lien, E.C.; Mayers, J.R.; Tai, K.; Lau, A.N.; Jones-Sali, P.; et al. Altered exocrine function can drive adipose wasting in early pancreatic cancer. Nature 2018, 558, 600-604. [CrossRef] [PubMed]

6. Rahib, L.; Smith, B.D.; Aizenberg, R.; Rosenzweig, A.B.; Fleshman, J.M.; Matrisian, L.M. Projecting cancer incidence and deaths to 2030: The unexpected burden of thyroid, liver, and pancreas cancers in the United States. Cancer Res. 2014, 74, 2913-2921. [CrossRef] [PubMed]

7. Rossi, M.L.; Rehman, A.A.; Gondi, C.S. Therapeutic options for the management of pancreatic cancer. World J. Gastroenterol. 2014, 20, 11142-11159. [CrossRef] [PubMed]

8. Hegewisch-Becker, S.; Aldaoud, A.; Wolf, T.; Krammer-Steiner, B.; Linde, H.; Scheiner-Sparna, R.; Hamm, D.; Jänicke, M.; Marschner, N. Results from the prospective German TPK clinical cohort study: Treatment algorithms and survival of 1174 patients with locally advanced, inoperable or metastatic pancreatic ductal adenocarcinoma. Int. J. Cancer 2018. [CrossRef]

9. Pishvaian, M.J.; Bender, R.J.; Halverson, D.; Rahib, L.; Hendifar, A.E.; Mikhail, S.; Chung, V.; Picozzi, V.J.; Sohal, D.; Blais, E.M.; et al. Molecular profiling of pancreatic cancer patients: Initial results from the know your tumor initiative. Clin. Cancer Res. 2018. [CrossRef] [PubMed]

10. Rouanet, M.; Lebrin, M.; Gross, F.; Bournet, B.; Cordelier, P.; Buscail, L. Gene therapy for pancreatic cancer: Specificity, issues and hopes. Int. J. Mol. Sci. 2017, 18, 1231. [CrossRef] [PubMed]

11. Hu, C.; Hart, S.N.; Polley, E.C.; Gnanaolivu, R.; Shimelis, H.; Lee, K.Y.; Lilyquist, J.; Na, J.; Moore, R.; Antwi, S.O.; et al. Association Between inherited germline mutations in cancer predisposition genes and risk of pancreatic cancer. JAMA 2018, 319, 2401-2409. [CrossRef] [PubMed]

12. Di Magliano, M.P.; Logsdon, C.D. Roles for KRAS in pancreatic tumor development and progression. Gastroenterology 2013, 144, 1220-1229. [CrossRef] [PubMed]

13. Waddell, N.; Pajic, M.; Patch, A.M.; Chang, D.K.; Kassahn, K.S.; Bailey, P.; Johns, A.L.; Miller, D.; Nones, K.; Quek, K.; et al. Whole genomes redefine the mutational landscape of pancreatic cancer. Nature 2015, 518, 495-501. [CrossRef] [PubMed]

14. Fu, Y.; Liu, X.; Chen, Q.; Liu, T.; Lu, C.; Yu, J.; Miao, Y.; Wei, J. Downregulated miR-98-5p promotes PDAC proliferation and metastasis by reversely regulating MAP4K4. J. Exp. Clin. Cancer Res. 2018, 37, 130. [CrossRef] [PubMed]

15. Huynh, D.L.; Zhang, J.J.; Chandimali, N.; Ghosh, M.; Gera, M.; Kim, N.; Park, Y.H.; Kwon, T.; Jeong, D.K. SALL4 suppresses reactive oxygen species in pancreatic ductal adenocarcinoma phenotype via FoxM1/Prx III axis. Biochem. Biophys. Res. Commun. 2018, 503, 2248-2254. [CrossRef] [PubMed]

16. Liu, B.; Yang, H.; Taher, L.; Denz, A.; Grützmann, R.; Pilarsky, C.; Weber, G.F. Identification of Prognostic Biomarkers by Combined mRNA and miRNA Expression microarray Analysis in Pancreatic Cancer. Transl. Oncol. 2018, 11, 700-714. [CrossRef] [PubMed] 
17. Wang, W.Q.; Liu, L.; Xu, H.X.; Wu, C.T.; Xiang, J.F.; Xu, J.; Liu, C.; Long, J.; Ni, Q.X.; Yu, X.J. Infiltrating immune cells and gene mutations in pancreatic ductal adenocarcinoma. Br. J. Surg. 2016, 103, 1189-1199. [CrossRef] [PubMed]

18. Patra, K.C.; Kato, Y.; Mizukami, Y.; Widholz, S.; Boukhali, M.; Revenco, I.; Grossman, E.A.; Ji, F.; Sadreyev, R.I.; Liss, A.S.; et al. Mutant GNAS drives pancreatic tumourigenesis by inducing PKA-mediated SIK suppression and reprogramming lipid metabolism. Nat. Cell. Biol. 2018, 20, 811-822. [CrossRef] [PubMed]

19. Gilly, F.N.; Beaujard, A.; Bienvenu, J.; Trillet Lenoir, V.; Glehen, O.; Thouvenot, D.; Malcus, C.; Favrot, M.; Dumontet, C.; Lombard-Bohas, C.; et al. Gene therapy with Adv-IL-2 in unresectable digestive cancer: Phase I-II study, intermediate report. HepatoGastroenterology 1999, 46, 1268-1273. [PubMed]

20. Mulvihill, S.; Warren, R.; Venook, A.; Adler, A.; Randlev, B.; Heise, C.; Kirn, D. Safety and feasibility of injection with an E1B-55 kDa gene-deleted, replication-selective adenovirus (ONYX-015) into primary carcinomas of the pancreas: A phase I trial. Gene Ther. 2001, 8, 308-315. [CrossRef] [PubMed]

21. Salmons, B.; Löhr, M.; Günzburg, W.H. Treatment of inoperable pancreatic carcinoma using a cell-based local chemotherapy: Results of a phase I/II clinical trial. J. Gastroenterol. 2003, 38, 78-84. [PubMed]

22. Pecher, G.; Häring, A.; Kaiser, L.; Thiel, E. Mucin gene (MUC1) transfected dendritic cells as vaccine: Results of a phase I/II clinical trial. Cancer Immunol. Immunother. 2002, 51, 669-673. [CrossRef] [PubMed]

23. Hecht, J.R.; Bedford, R.; Abbruzzese, J.L.; Lahoti, S.; Reid, T.R.; Soetikno, R.M.; Kirn, D.H.; Freeman, S.M. A phase I/II trial of intratumoral endoscopic ultrasound injection of ONYX-015 with intravenous gemcitabine in unresectable pancreatic carcinoma. Clin. Cancer Res. 2003, 9, 555-561. [PubMed]

24. Gordon, E.M.; Cornelio, G.H.; Lorenzo, C.C., 3rd; Levy, J.P.; Reed, R.A.; Liu, L.; Hall, F.L. First clinical experience using a 'pathotropic' injectable retroviral vector (Rexin-G) as intervention for stage IV pancreatic cancer. Int. J. Oncol. 2004, 24, 177-185. [CrossRef] [PubMed]

25. Sangro, B.; Mazzolini, G.; Ruiz, J.; Herraiz, M.; Quiroga, J.; Herrero, I.; Benito, A.; Larrache, J.; Pueyo, J.; Subtil, J.C.; et al. Phase I trial of intratumoral injection of an adenovirus encoding interleukin-12 for advanced digestive tumors. J. Clin. Oncol. 2004, 22, 1389-1397. [CrossRef] [PubMed]

26. Senzer, N.; Mani, S.; Rosemurgy, A.; Nemunaitis, J.; Cunningham, C.; Guha, C.; Bayol, N.; Gillen, M.; Chu, K.; Rasmussen, C.; et al. TNFerade biologic, an adenovector with a radiation-inducible promoter, carrying the human tumor necrosis factor alpha gene: A phase I study in patients with solid tumors. J. Clin. Oncol. 2004, 22, 592-601. [CrossRef] [PubMed]

27. Mazzolini, G.; Alfaro, C.; Sangro, B.; Feijoó, E.; Ruiz, J.; Benito, A.; Tirapu, I.; Arina, A.; Sola, J.; Herraiz, M.; et al. Intratumoral injection of dendritic cells engineered to secrete interleukin-12 by recombinant adenovirus in patients with metastatic gastrointestinal carcinomas. J. Clin. Oncol. 2005, 23, 999-1010. [CrossRef] [PubMed]

28. Kaufman, H.L.; Kim-Schulze, S.; Manson, K.; DeRaffele, G.; Mitcham, J.; Seo, K.S.; Kim, D.W.; Marshall, J. Poxvirus-based vaccine therapy for patients with advanced pancreatic cancer. J. Transl. Med. 2007, 5, 60. [CrossRef] [PubMed]

29. Laheru, D.; Lutz, E.; Burke, J.; Biedrzycki, B.; Solt, S.; Onners, B.; Tartakovsky, I.; Nemunaitis, J.; Le, D.; Sugar, E.; et al. Allogeneic granulocyte macrophage colony-stimulating factor-secreting tumor immunotherapy alone or in sequence with cyclophosphamide for metastatic pancreatic cancer: A pilot study of safety, feasibility, and immune activation. Clin. Cancer Res. 2008, 14, 1455-1463. [CrossRef] [PubMed]

30. Chawla, S.P.; Chua, V.S.; Fernandez, L.; Quon, D.; Blackwelder, W.C.; Gordon, E.M.; Hall, F.L. Advanced phase I/II studies of targeted gene delivery in vivo: Intravenous Rexin-G for gemcitabine-resistant metastatic pancreatic cancer. Mol. Ther. 2010, 18, 435-441. [CrossRef] [PubMed]

31. Nakao, A.; Kasuya, H.; Sahin, T.T.; Nomura, N.; Kanzaki, A.; Misawa, M.; Shirota, T.; Yamada, S.; Fujii, T.; Sugimoto, H.; et al. A phase I dose-escalation clinical trial of intraoperative direct intratumoral injection of HF10 oncolytic virus in non-resectable patients with advanced pancreatic cancer. Cancer Gene Ther. 2011, 18, 167-175. [CrossRef] [PubMed]

32. Kubuschok, B.; Pfreundschuh, M.; Breit, R.; Hartmann, F.; Sester, M.; Gärtner, B.; König, J.; Murawski, N.; Held, G.; Zwick, C.; et al. Mutated Ras-transfected, EBV-transformed lymphoblastoid cell lines as a model tumor vaccine for boosting T-cell responses against pancreatic cancer: A pilot trial. Hum. Gene Ther. 2012, 23, 1224-1236. [CrossRef] [PubMed] 
33. Hanna, N.; Ohana, P.; Konikoff, F.M.; Leichtmann, G.; Hubert, A.; Appelbaum, L.; Kopelman, Y.; Czerniak, A.; Hochberg, A. Phase 1/2a, dose-escalation, safety, pharmacokinetic and preliminary efficacy study of intratumoral administration of BC-819 in patients with unresectable pancreatic cancer. Cancer Gene Ther. 2012, 19, 374-381. [CrossRef] [PubMed]

34. Hecht, J.R.; Farrell, J.J.; Senzer, N.; Nemunaitis, J.; Rosemurgy, A.; Chung, T.; Hanna, N.; Chang, K.J.; Javle, M.; Posner, M.; et al. EUS or percutaneously guided intratumoral TNFerade biologic with 5-fluorouracil and radiotherapy for first-line treatment of locally advanced pancreatic cancer: A phase I/II study. Gastrointest. Endosc. 2012, 75, 332-338. [CrossRef] [PubMed]

35. Le, D.T.; Brockstedt, D.G.; Nir-Paz, R.; Hampl, J.; Mathur, S.; Nemunaitis, J.; Sterman, D.H.; Hassan, R.; Lutz, E.; Moyer, B.; et al. A live-attenuated listeria vaccine (ANZ-100) and a live-attenuated listeria vaccine expressing mesothelin (CRS-207) for advanced cancers: Phase I studies of safety and immune induction. Clin. Cancer Res. 2012, 18, 858-868. [CrossRef] [PubMed]

36. Hardacre, J.M.; Mulcahy, M.; Small, W.; Talamonti, M.; Obel, J. Addition of algenpantucel-L immunotherapy to standard adjuvant therapy for pancreatic cancer: A phase 2 study. J. Gastrointest. Surg. 2013, 17, 94-100; discussion 100-101. [CrossRef] [PubMed]

37. Herman, J.M.; Wild, A.T.; Wang, H.; Tran, P.T.; Chang, K.J.; Taylor, G.E.; Donehower, R.C.; Pawlik, T.M.; Ziegler, M.A.; Cai, H.; et al. Randomized phase III multi-institutional study of TNFerade biologic with fluorouracil and radiotherapy for locally advanced pancreatic cancer: Final results. J. Clin. Oncol. 2013, 31, 886-894. [CrossRef] [PubMed]

38. Löhr, J.M.; Haas, S.L.; Kröger, J.C.; Friess, H.M.; Höft, R.; Goretzki, P.E.; Peschel, C.; Schweigert, M.; Salmons, B.; Gunzburg, W.H. Encapsulated cells expressing a chemotherapeutic activating enzyme allow the targeting of subtoxic chemotherapy and are safe and efficacious: Data from two clinical trials in pancreatic cancer. Pharmaceutics 2014, 6, 447-466. [CrossRef] [PubMed]

39. Aguilar, L.K.; Shirley, L.A.; Chung, V.M.; Marsh, C.L.; Walker, J.; Coyle, W.; Marx, H.; Bekaii-Saab, T.; Lesinski, G.B.; Swanson, B.; et al. Gene-mediated cytotoxic immunotherapy as adjuvant to surgery or chemoradiation for pancreatic adenocarcinoma. Cancer Immunol. Immunother. 2015, 64, 727-736. [CrossRef] [PubMed]

40. Golan, T.; Khvalevsky, E.Z.; Hubert, A.; Gabai, R.M.; Hen, N.; Segal, A.; Domb, A.; Harari, G.; David, E.B.; Raskin, S.; et al. RNAi therapy targeting KRAS in combination with chemotherapy for locally advanced pancreatic cancer patients. Oncotarget 2015, 6, 24560-24570. [CrossRef] [PubMed]

41. Le, D.T.; Wang-Gillam, A.; Picozzi, V.; Greten, T.F.; Crocenzi, T.; Springett, G.; Morse, M.; Zeh, H.; Cohen, D.; Fine, R.L.; et al. Safety and survival with GVAX pancreas prime and Listeria monocytogenes-expressing mesothelin (CRS-207) boost vaccines for metastatic pancreatic cancer. J. Clin. Oncol. 2015, 33, 1325-1333. [CrossRef] [PubMed]

42. Noonan, A.M.; Farren, M.R.; Geyer, S.M.; Huang, Y.; Tahiri, S.; Ahn, D.; Mikhail, S.; Ciombor, K.K.; Pant, S.; Aparo, S.; et al. Randomized Phase 2 trial of the oncolytic virus Pelareorep (Reolysin) in upfront treatment of metastatic pancreatic adenocarcinoma. Mol. Ther. 2016, 24, 1150-1158. [CrossRef] [PubMed]

43. Inoko, K.; Hiraoka, K.; Inagaki, A.; Takahashi, M.; Kushibiki, T.; Hontani, K.; Takano, H.; Sato, S.; Takeuchi, S.; Nakamura, T.; et al. Therapeutic activity of retroviral replicating vector-mediated prodrug activator gene therapy for pancreatic cancer. Cancer Gene Ther. 2018. [CrossRef] [PubMed]

44. Buscail, L.; Bournet, B.; Vernejoul, F.; Cambois, G.; Lulka, H.; Hanoun, N.; Dufresne, M.; Meulle, A.; Vignolle-Vidoni, A.; Ligat, L.; et al. First-in-man phase 1 clinical trial of gene therapy for advanced pancreatic cancer: Safety, biodistribution, and preliminary clinical findings. Mol. Ther. 2015, 23, 779-789. [CrossRef] [PubMed]

45. Galanis, E.; Carlson, S.K.; Foster, N.R.; Lowe, V.; Quevedo, F.; McWilliams, R.R.; Grothey, A.; Jatoi, A.; Alberts, S.R.; Rubin, J. Phase I trial of a pathotropic retroviral vector expressing a cytocidal cyclin G1 construct (Rexin-G) in patients with advanced pancreatic cancer. Mol. Ther. 2008, 16, 979-984. [CrossRef] [PubMed]

46. Lutz, E.; Yeo, C.J.; Lillemoe, K.D.; Biedrzycki, B.; Kobrin, B.; Herman, J.; Sugar, E.; Piantadosi, S.; Cameron, J.L.; Solt, S.; et al. A lethally irradiated allogeneic granulocyte-macrophage colony stimulating factor-secreting tumor vaccine for pancreatic adenocarcinoma. A Phase II trial of safety, efficacy, and immune activation. Ann. Surg. 2011, 253, 328-335. [CrossRef] [PubMed] 
47. Le, D.T.; Lutz, E.; Uram, J.N.; Sugar, E.A.; Onners, B.; Solt, S.; Zheng, L.; Diaz, L.A.; Donehower, R.C.; Jaffee, E.M.; et al. Evaluation of ipilimumab in combination with allogeneic pancreatic tumor cells transfected with a GM-CSF gene in previously treated pancreatic cancer. J Immunother 2013, 36, 382-389. [CrossRef] [PubMed]

48. Thakar, M.; Hu, Y.; Morreale, M.; Lerner, L.; Ying Lin, W.; Sen, R.; Cai, Y.; Karunasena, E.; Thakar, M.; Saggi, S.; et al. A novel epigenetic modulating agent sensitizes pancreatic cells to a chemotherapy agent. PLoS ONE 2018, 13, e0199130. [CrossRef] [PubMed]

49. Hill, R.; Rabb, M.; Madureira, P.A.; Clements, D.; Gujar, S.A.; Waisman, D.M.; Giacomantonio, C.A.; Lee, P.W. Gemcitabine-mediated tumour regression and p53-dependent gene expression: Implications for colon and pancreatic cancer therapy. Cell Death Dis. 2013, 4, e791. [CrossRef] [PubMed]

50. Liu, B.; Yang, H.; Pilarsky, C.; Weber, G.F. The Effect of GPRC5a on the Proliferation, Migration Ability, Chemotherapy Resistance, and Phosphorylation of GSK-3 $\beta$ in Pancreatic Cancer. Int. J. Mol. Sci. 2018, 19, 1870. [CrossRef] [PubMed]

51. Ginn, S.L.; Amaya, A.K.; Alexander, I.E.; Edelstein, M.; Abedi, M.R. Gene therapy clinical trials worldwide to 2017: An update. J. Gene Med. 2018, 20, e3015. [CrossRef] [PubMed]

52. Vassaux, G.; Angelova, A.; Baril, P.; Midoux, P.; Rommelaere, J.; Cordelier, P. The Promise of gene therapy for pancreatic cancer. Hum. Gene Ther. 2016, 27, 127-133. [CrossRef] [PubMed]

53. Tysome, J.R.; Briat, A.; Alusi, G.; Cao, F.; Gao, D.; Yu, J.; Wang, P.; Yang, S.; Dong, Z.; Wang, S.; et al. Lister strain of vaccinia virus armed with endostatin-angiostatin fusion gene as a novel therapeutic agent for human pancreatic cancer. Gene Ther. 2009, 16, 1223-1233. [CrossRef] [PubMed]

54. Sicard, F.; Gayral, M.; Lulka, H.; Buscail, L.; Cordelier, P. Targeting miR-21 for the therapy of pancreatic cancer. Mol. Ther. 2013, 21, 986-994. [CrossRef] [PubMed]

55. Hassan, F.; Lossie, S.L.; Kasik, E.P.; Channon, A.M.; Ni, S.; Kennedy, M.A. A mouse model study of toxicity and biodistribution of a replication defective adenovirus serotype 5 virus with its genome engineered to contain a decoy hyper binding site to sequester and suppress oncogenic HMGA1 as a new cancer treatment therapy. PLoS ONE 2018, 13, e0192882. [CrossRef] [PubMed]

56. Chen, M.; Maeng, K.; Nawab, A.; Francois, R.A.; Bray, J.K.; Reinhard, M.K.; Boye, S.L.; Hauswirth, W.W.; Kaye, F.J.; Aslanidi, G.; et al. Efficient gene delivery and expression in pancreas and pancreatic tumors by capsid-optimized AAV8 vectors. Hum. Gene Ther. Methods 2017, 28, 49-59. [CrossRef] [PubMed]

57. Lucas, T.; Benihoud, K.; Vigant, F.; Schmidt, C.Q.; Wortmann, A.; Bachem, M.G.; Simmet, T.; Kochanek, S. Hexon modification to improve the activity of oncolytic adenovirus vectors against neoplastic and stromal cells in pancreatic cancer. PLoS ONE 2015, 10, e0117254. [CrossRef] [PubMed]

58. Gayral, M.; Lulka, H.; Hanoun, N.; Biollay, C.; Sèlves, J.; Vignolle-Vidoni, A.; Berthommé, H.; Trempat, P.; Epstein, A.L.; Buscail, L.; et al. Targeted oncolytic herpes simplex virus type 1 eradicates experimental pancreatic tumors. Hum. Gene Ther. 2015, 26, 104-113. [CrossRef] [PubMed]

59. Rejiba, S.; Bigand, C.; Parmentier, C.; Masmoudi, A.; Hajri, A. Oncosuppressive suicide gene virotherapy "PVH1-yCD/5-FC" for pancreatic peritoneal carcinomatosis treatment: NF- $\mathrm{BB}$ and Akt/PI3K involvement. PLoS ONE 2013, 8, e70594. [CrossRef] [PubMed]

60. Chew, W.L.; Tabebordbar, M.; Cheng, J.K.; Mali, P.; Wu, E.Y.; Ng, A.H.; Zhu, K.; Wagers, A.J.; Church, G.M. A multifunctional AAV-CRISPR-Cas9 and its host response. Nat. Methods 2016, 13, 868-874. [CrossRef]

61. Chiou, S.H.; Winters, I.P.; Wang, J.; Naranjo, S.; Dudgeon, C.; Tamburini, F.B.; Brady, J.J.; Yang, D.; Grüner, B.M.; Chuang, C.H.; et al. Pancreatic cancer modeling using retrograde viral vector delivery and in vivo CRISPR/Cas9-mediated somatic genome editing. Genes Dev. 2015, 29, 1576-1585. [CrossRef] [PubMed]

62. Seo, Y.D.; Pillarisetty, V.G. T-cell programming in pancreatic adenocarcinoma: A review. Cancer Gene Ther. 2017, 24, 106-113. [CrossRef] [PubMed]

63. Mohammed, S.; Sukumaran, S.; Bajgain, P.; Watanabe, N.; Heslop, H.E.; Rooney, C.M.; Brenner, M.K.; Fisher, W.E.; Leen, A.M.; Vera, J.F. Improving chimeric antigen receptor-modified T cell function by reversing the immunosuppressive tumor microenvironment of pancreatic cancer. Mol. Ther. 2017, 25, 249-258. [CrossRef] [PubMed]

64. DeSelm, C.J.; Tano, Z.E.; Varghese, A.M.; Adusumilli, P.S. CAR T-cell therapy for pancreatic cancer. J. Surg. Oncol. 2017, 116, 63-74. [CrossRef] [PubMed]

65. Gonska, T. Genetic predisposition in pancreatitis. Curr. Opin. Pediatr. 2018, 30, 660-664. [CrossRef] [PubMed] 
66. Gaudet, D.; Stroes, E.S.; Méthot, J.; Brisson, D.; Tremblay, K.; Bernelot Moens, S.J.; Iotti, G.; Rastelletti, I.; Ardigo, D.; Corzo, D.; et al. Long-term retrospective analysis of gene therapy with alipogene tiparvovec and its effect on lipoprotein lipase deficiency-induced pancreatitis. Hum. Gene Ther. 2016, 27, 916-925. [CrossRef] [PubMed]

67. Talukdar, R.; Reddy, D.N. Pain in chronic pancreatitis: Managing beyond the pancreatic duct. World J. Gastroenterol. 2013, 19, 6319-6328. [CrossRef] [PubMed]

68. Liu, L.; Zhu, Y.; Noë, M.; Li, Q.; Pasricha, P.J. Neuronal transforming growth factor beta signaling via SMAD3 contributes to pain in animal models of chronic pancreatitis. Gastroenterology 2018, 154, 2252-2265. [CrossRef] [PubMed]

69. Lu, Y.; McNearney, T.A.; Lin, W.; Wilson, S.P.; Yeomans, D.C.; Westlund, K.N. Treatment of inflamed pancreas with enkephalin encoding HSV-1 recombinant vector reduces inflammatory damage and behavioral sequelae. Mol. Ther. 2007, 15, 1812-1819. [CrossRef] [PubMed]

70. Yang, H.; McNearney, T.A.; Chu, R.; Lu, Y.; Ren, Y.; Yeomans, D.C.; Wilson, S.P.; Westlund, K.N. Enkephalin-encoding herpes simplex virus-1 decreases inflammation and hotplate sensitivity in a chronic pancreatitis model. Mol. Pain 2008, 4, 8. [CrossRef] [PubMed]

71. Demirbilek, H.; Hatipoglu, N.; Gul, U.; Tatli, Z.U.; Ellard, S.; Flanagan, S.E.; De Franco, E.; Kurtoglu, S. Permanent neonatal diabetes mellitus and neurological abnormalities due to a novel homozygous missense mutation in NEUROD1. Pediatr. Diabetes 2018, 19, 898-904. [CrossRef] [PubMed]

72. Handorf, A.M.; Sollinger, H.W.; Alam, T. Insulin gene therapy for type 1 diabetes mellitus. Exp. Clin. Transplant. 2015, 13, 37-45. [PubMed]

73. Sponton, C.H.; Kajimura, S. AAV-mediated gene therapy as a strategy to fight obesity and metabolic diseases. EMBO Mol. Med. 2018, 10, e9431. [CrossRef] [PubMed]

74. Tasyurek, M.H.; Altunbas, H.A.; Canatan, H.; Griffith, T.S.; Sanlioglu, S. GLP-1-mediated gene therapy approaches for diabetes treatment. Expert Rev. Mol. Med. 2014, 16, e7. [CrossRef] [PubMed]

75. Wang, Y.; Dorrell, C.; Naugler, W.E.; Heskett, M.; Spellman, P.; Li, B.; Galivo, F.; Haft, A.; Wakefield, L.; Grompe, M. Long-term correction of diabetes in mice by in vivo reprogramming of pancreatic ducts. Mol. Ther. 2018, 26, 1327-1342. [CrossRef] [PubMed]

76. Pan, G.; Hao, H.; Liu, J. Induction of hepatocytes-derived insulin-producing cells using small molecules and identification of microRNA profiles during this procedure. Biochem. Biophys. Res. Commun. 2018, 498, 646-653. [CrossRef] [PubMed]

77. Zickri, M.B.; Aboul-Fotouh, G.I.; Omar, A.I.; El-Shafei, A.A.; Reda, A.M. Effect of stem cells and gene transfected stem cells therapy on the pancreas of experimentally induced Type 1 diabetes. Int. J. Stem Cells 2018. [CrossRef] [PubMed]

78. Jimenez, V.; Jambrina, C.; Casana, E.; Sacristan, V.; Muñoz, S.; Darriba, S.; Rodó, J.; Mallol, C.; Garcia, M.; León, X.; et al. FGF21 gene therapy as treatment for obesity and insulin resistance. EMBO Mol. Med. 2018, 10. [CrossRef] [PubMed]

79. Kamimura, K.; Suda, T.; Zhang, G.; Liu, D. Advances in gene delivery systems. Pharmaceut. Med. 2011, 25, 293-306. [CrossRef] [PubMed]

80. Ogawa, K.; Kamimura, K.; Kobayashi, Y.; Abe, H.; Yokoo, T.; Sakai, N.; Nagoya, T.; Sakamaki, A.; Abe, S.; Hayashi, K.; et al. Efficacy and safety of pancreas-targeted hydrodynamic gene delivery in rats. Mol. Ther. Nucleic Acids 2017, 9, 80-88. [CrossRef] [PubMed]

81. Khan, O.F.; Kowalski, P.S.; Doloff, J.C.; Tsosie, J.K.; Bakthavatchalu, V.; Winn, C.B.; Haupt, J.; Jamiel, M.; Langer, R.; Anderson, D.G. Endothelial siRNA delivery in nonhuman primates using ionizable low-molecular weight polymeric nanoparticles. Sci Adv. 2018, 4, eaar8409. [CrossRef] [PubMed]

82. Gorgulu, K.; Diakopoulos, K.N.; Ai, J.; Schoeps, B.; Kabacaoglu, D.; Karpathaki, AF.; Ciecielski, K.J.; Kaya-Aksoy, E.; Ruess, D.A.; Berninger, A.; et al. Levels of the autophagy related 5 protein affect progression and metastasis of pancreatic tumors in mice. Gastroenterology 2018. [CrossRef] [PubMed]

(C) 2018 by the authors. Licensee MDPI, Basel, Switzerland. This article is an open access article distributed under the terms and conditions of the Creative Commons Attribution (CC BY) license (http:/ / creativecommons.org/licenses/by/4.0/). 